\title{
Determining the Quality and Quantity of Bioethanol Production using Golden Shower (Cassica fistula) Fruit
}

\author{
Amy Lizbeth J. Rico \\ College of Engineering and Technology, Tarlac Agricultural University, Philippines \\ E-mail: amylizbethjrico@gmail.com \\ ORCID ID: https://orcid.org/0000-0001-8206-2827
}

Received 10/12/2020, Accepted 11/3/2021, Published 30/3/2021

This work is licensed under a Creative Commons Attribution 4.0 International License.

\begin{abstract}
:
Depletion of fossil fuel is one of the main reasons why the bioethanol has become popular. It is a renewable energy source. In order to meet the great demand of bioethanol, it is best that the bioethanol production is from cheap raw materials. Since the golden shower fruit is not being utilized and is considered as waste material, hence, this study was conducted to make use of the large volume of the residue as feedstock to test its potential for bioethanol extraction. The main goal of this study is to obtain the most volume of bioethanol from the golden shower fruit liquid residue by the factors, days of fermentation $(3,5$, and 7 days) and sugar concentration (15, 20 and 25 brix) of the liquid residue. Also, part of the study is to compute the cost of production in extracting bioethanol from the golden shower fruit. Each treatment was replicated three (3) times. The Two-Factorial Analysis of Variance (ANOVA) of the Complete Randomized Design (CRD) was used to analyze the treatments. Treatments means were compared using the Duncan's Multiple Range Test (DMRT).
\end{abstract}

Keywords: Bioethanol, Extraction, Fermentation, Renewable Energy, Waste.

\section{Introduction:}

In recent years, one of the serious problems that our country as well as the world has been facing is the energy crisis. Furthermore, the demand for fossil fuels has increased over the past few decades.

Bioethanol, which is considered one of the renewable energy sources, production became popular because of the rapid decrease of the fossil fuels. Because of this, exhaust gases of bio ethanol are much cleaner combustion that fossil fuels. Bioethanol production can lead to healthy environment because of the lower emission of air pollutants as well as the carbon neutral. Its production may also lead to free sulfur and aromatic. Sugar feedstock from starch is the main ingredient in the production of bioethanol globally. She also stated that out of the total production, $61 \%$ is accounted to sugar crops while the remaining $39 \%$ is derived from starch as feedstock. In the Philippines, sugarcane is the main component for the production of ethanol while in the United States; corn is considered the main component in their bioethanol production. Nevertheless, considering the increasing demand for human food, using this feedstock for bioethanol production may be a competitor for human and livestock consumption.

In order to meet the great demand of bioethanol, it is best that the bioethanol production is from cheap raw materials. In this case, production of bioethanol should be derived from cheap raw materials such as agricultural wastes, fruit wastes, vegetable wastes, municipal and industrial wastes.

Materials that contain sugar such molasses, sugarcane (cane juice or cane syrup), cereal crops, sugar beet and sweet sorghum and other materials that contain sugar are fermented to produce bioethanol. Increasing focus on using the lignocellulosic biomass became the result of the development in the biotechnology (1). In these studies, the lignocellulosic biomass is used in the production of liquid fuels and other chemical that is used in bioethanol production. Many biomass substrates have high content of cellulose and hemicellulose and have been enumerated to be of great potential for bioethanol production. The pretreatment step of the raw materials is the main challenge in the conversion of ethanol from biomass. In the pretreatment step, the structure of 
the ligocellulosic complex needs to be degraded (2). The steps that need to be done in the pretreatment are the removal of lignin, the partial or total hydrolysis of the hemicellulose, the decrease in the fraction of crystalline cellulose, and subsequently, the hydrolysis step. In the hydrolysis step, in order to obtain glucose that is converted into ethanol by microorganisms, the cellulose undergoes enzymatic hydrolysis (3). Eventually, ethanol is the result of the conversion of the sugars that is released during the hydrolysis of hemicellulose (4). Industrially, two processes can be used in the hydrolysis and fermentation of the pretreated materials; the separate hydrolysis and fermentation (SHF). Hydrolysis or fermentation can also be done in one single step as identified to be simultaneous saccharification and fermentation (SSF) (5). There are species that have been reported that has the ability to directly ferment cellulose into ethanol. These species are Neurospora, Monilia, Paecilomyces and Fusarium sp (6).
A flowering plant in the family Fabaceae is the golden shower or the Cassia fistula. The golden shower tree is a medium-sized tree which grows to 10-20 meters tall and is fast growing tree. Since the fruit of golden shower is considered as waste material, hence, this study was conducted to make use of the large volume of the residue as feedstock to test its potential for bioethanol extraction.

The objective of the study is to obtain bioethanol from golden shower fruit residues. Specifically, it aims to determine the volume of ethanol produced based on the duration of fermentation and sugar content of the feedstock, and to determine the cost of bioethanol production from golden shower fruit.

\section{Materials and Methods:}

The flow diagram in the production of bioethanol from golden shower fruit is shown in Fig. 1. The following is the process used in the production of bioethanol from golden shower fruit.
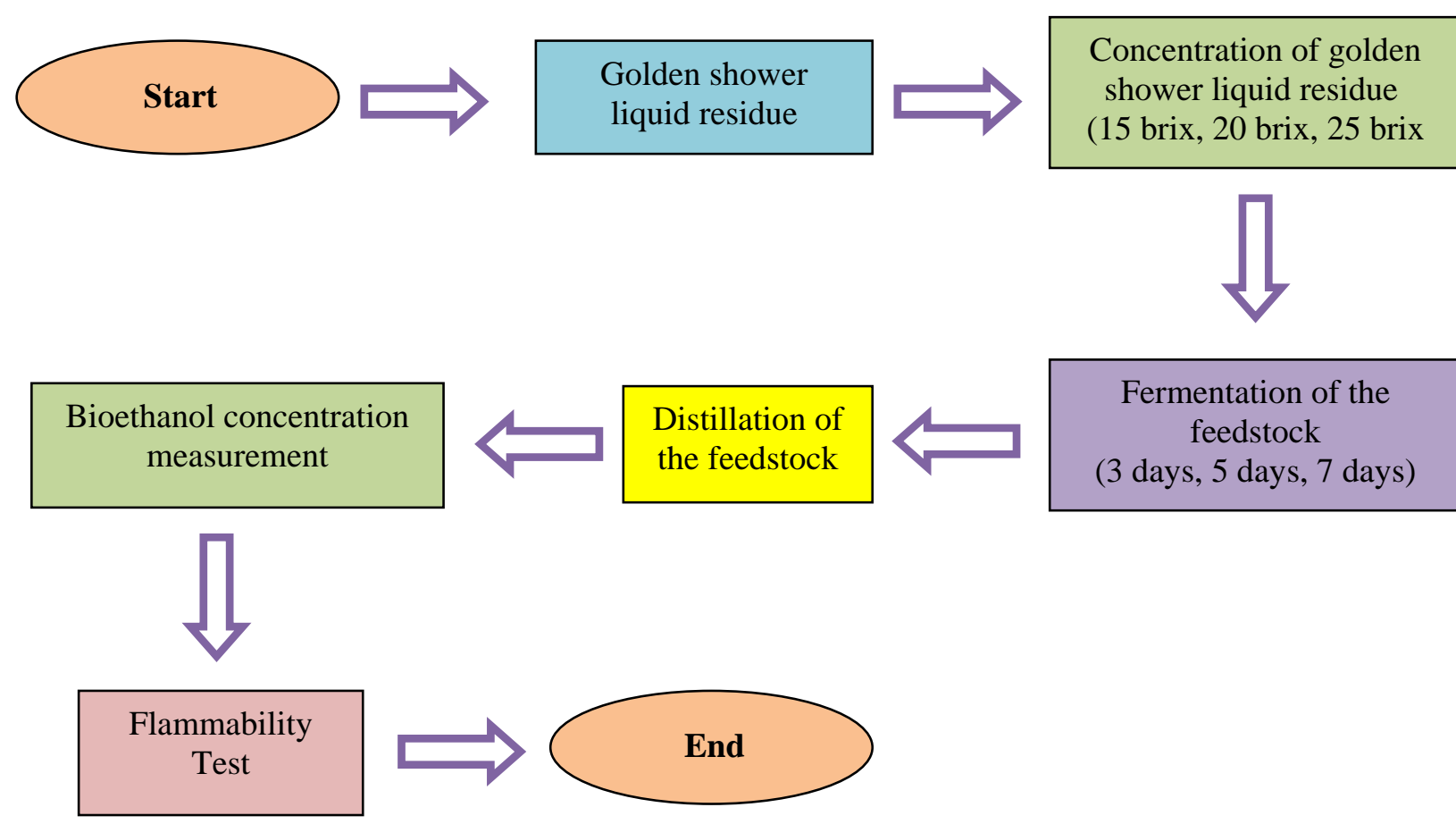

Figure 1. Flow diagram of the production of bioethanol from golden shower fruit.

\section{Collection of Raw Materials}

The golden shower fruit was collected from a farm in Camiling, Tarlac. Only the matured fruits are collected. The collected golden shower fruit were chopped using a multi-crop chopper available in the University. Twenty - five kilograms $(25 \mathrm{~kg})$ of chopped golden shower fruit with enough amount of water were boiled in a container (Fig. 2) for 6 hours. The boiled golden shower fruit was placed in a screen and poured with water to remove the gelatinous texture from the impurities. The poured water was collected and served as the liquid residue for the study. 


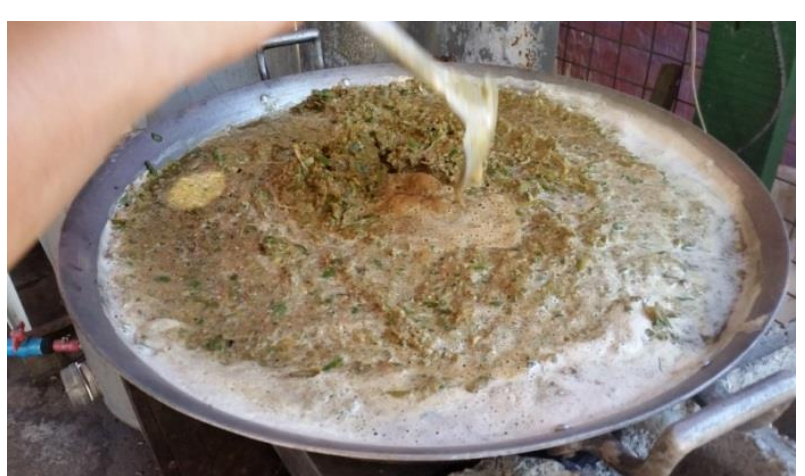

Figure 2. Golden shower fruit was boiled with enough amount of water.

\section{Concentration Process}

The initial sugar content of the golden shower fruit residue was measured using the refractometer. The refractometer was calibrated first by putting few drops of distilled water on the prism. The screw calibration was turned to adjust it to zero reading.

After calibrating the refractometer, a few drops of a sample from the liquid residue was placed on the prism and the sugar content was obtained and recorded. If the sugar content is below the desired sugar content, the golden shower fruit residue was heated until the desired sugar content of the feedstock was obtained.

The golden shower fruit liquid residue was divided into three parts. Each part was allowed to boil. The first batch of golden shower fruit liquid residue was boiled for 1.5 hours (1 hour and 30 minutes) to obtain the 15 brix. Wood and biomass stove was used as the source of heat. The golden shower fruit liquid residue was stirred continuously and the concentration of sugar was checked every 30 minutes using the refractometer.

The second part underwent through the same process, boiled and stirred continuously, until 20 brix was obtained. Also, sugar content was monitored at 30 minutes interval. After 2.5 hours, sugar content of 20 brix was obtained.

The third part was also boiled and stirred continuously until the sugar content reached 25 brix. Also, the sugar content was obtained every 30 minutes while boiling. After 3 hours, sugar content of 25 brix reading was obtained from the refractometer.

\section{Fermentation}

After attaining the desired sugar content in each part, the feedstock was set aside to cool down. For each sugar content level, nine liters of feedstock were obtained. One liter of the feedstock was measured (using the graduated cylinder) was placed in container.

Meanwhile, the optimum weight of yeast per liter of feedstock is $1.5 \mathrm{~g} / \mathrm{L}$. Yeast was weighed using the electronic scale. The yeast weighing 1.5 grams was dissolved in warm water and mixed continuously until bubbles appeared. The bubbles in the mixture indicate that the yeast is already active (7). In every container, a mixture of 1.5 grams of yeast was transferred into the liter of feedstock. An airlock using the hose and water seal (Fig. 3) were connected to the container to avoid the entry of air in the feedstock during the fermentation process. Absence of air should be done in the fermentation process to be able to produce bioethanol, otherwise, ethanoic acid will be produced (8).

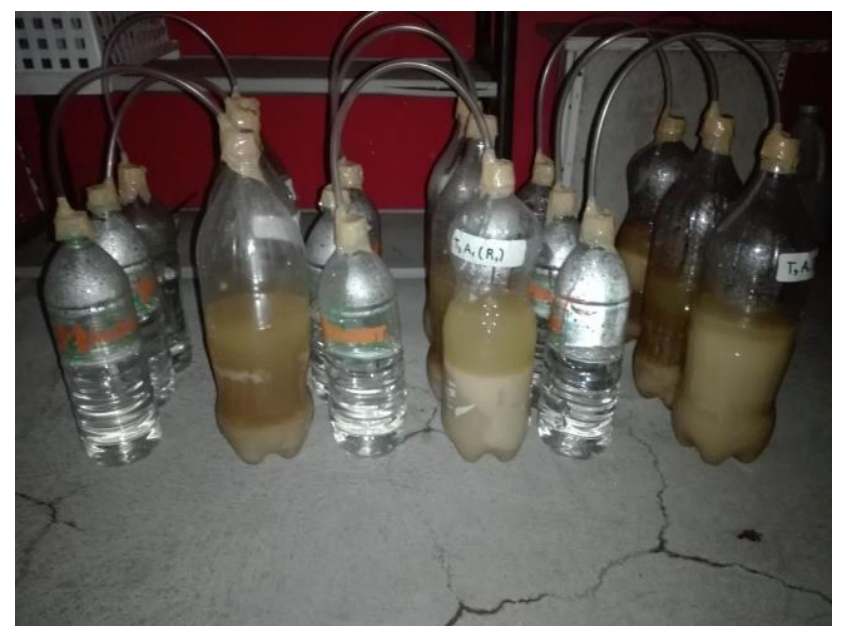

Figure 3. Airlock of the feedstock during the fermentation process.

The samples were placed in a shaded area. For each sugar content level, three liters were subjected 3 days of fermentation, other 3 liters to 5 days of fermentation, the remaining 3 liters were fermented for 7 days. The fermentation performance was monitored by weighing the fermentation bottles every 6 hours of fermentation. The weight loss is due to the product of fermentation, ethanol and carbon dioxide (9).

\section{Distillation}

In the extraction of bioethanol, distillation of the fermented feedstock took place. A reflux distiller was used to distill the feedstock. The sugar concentration of the fermented broth was checked in the refractometer before fermentation. In the fermentation process, the sugar is broken down with the aid of the yeast enzyme zymase. The gas that bubbles into the air is the carbon dioxide while the alcohol in the mixture with the water is the ethanol.

On the third day of fermentation, the feed stocks were placed in a reflux distiller and heated using the electric stove. The hose for the condenser of the distiller was connected to a tap water with a flow rate of $600 \mathrm{ml} / \mathrm{min}$. The water flow rate was measured by filling a container with a tap water 
within a minute. The amount of water was measured using a graduated cylinder. Too much flow of water in the condenser made it hard to reach a higher temperature to produce bioethanol. The desired temperature range for bioethanol production is $78^{\circ} \mathrm{C}$ to $98^{\circ} \mathrm{C}$. A thermostat is connected to the distiller to determine the temperature. After 20 minutes of heating, $78{ }^{\circ} \mathrm{C}$ was obtained and first drop of distillate was obtained. The distillation process was stopped when no distillate was collected. The collected distillates were measured using the graduated cylinder. The obtained volume was recorded. The same procedure was done for the 5 days and 7 days fermentation.

\section{Concentration of Ethanol}

The concentration of ethanol of the distillates was measured using the hydrometer. The collected distillates for each treatment were placed in a graduated cylinder. The hydrometer was allowed to float on the distillate as shown in Fig. 4. The concentration of the bioethanol was read and then recorded.

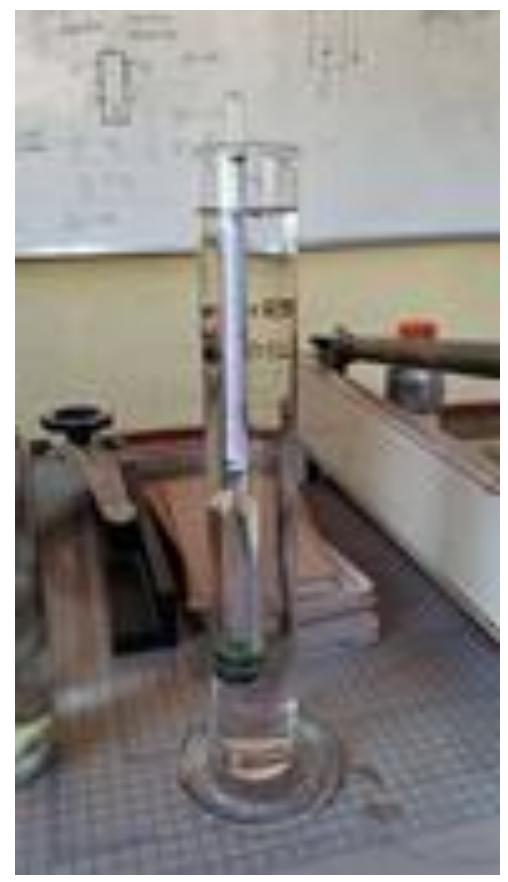

\section{Figure 4. Concentration of ethanol determination using the hydrometer.}

\section{Flammability Test}

To test the flammability of the obtained distillates, few drops of distillates from each sample were placed on the floor and lit using a lighter.

\section{Discussion:}

After the collection of the golden shower liquid residue, the sugar content was determined. The sugar content of the samples will determine the ability of the samples to be converted to bioethanol.
The obtained initial sugar content of the liquid residue was 3 brix. Fig. 5 shows the initial brix reading.

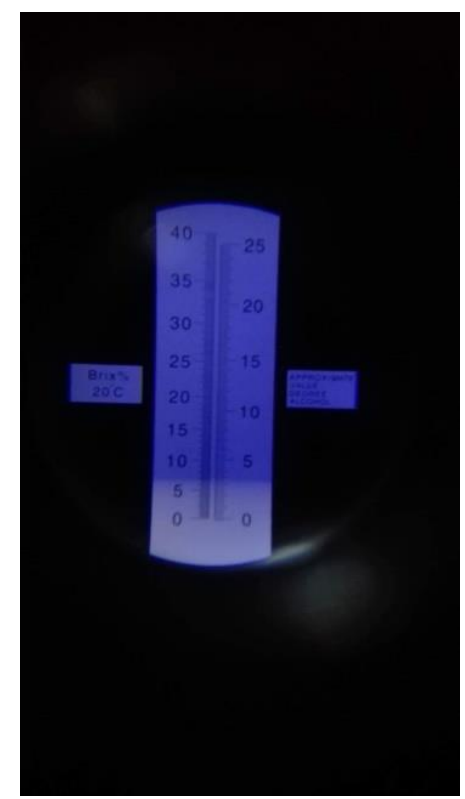

Figure 5. Initial brix reading using the refractometer.

The first batch of liquid residue was concentrated for 1.5 hours. After 60 minutes of boiling and continuous stirring, the sugar concentration of the liquid residue became 10 brix. The golden shower fruit liquid residue became 15 brix after another 90 minutes of continuous stirring. The second batch of liquid residue was concentrated for 2.5 hours. After 1 hour of the same procedure, the sugar content reading became 14 brix. After 2 hours and 30 minutes passed, the concentration of the sugar became 20 brix. The last batch of liquid residue was concentrated for 3 hours with the same procedure. After 150 minutes, the concentration of sugar in the broth became 18 brix. The sugar concentration became 25 brix after 180 minutes.

During fermentation, the weight of the samples was decreasing. The decrease in weight of the samples indicated active fermentation of the yeast. The sugar concentration of the feed stocks was read using the refractometer. The difference of the sugar content reading before and after fermentation shows the alcohol converted during the fermentation process.

Based from the results, the average extracted bioethanol from the samples is $77.96 \mathrm{~mL}$. Treatment T1A3 ( 25 brix $x 7$ days) gave the highest extracted bioethanol from the fermented feedstock with an amount of $139.33 \mathrm{~mL}$ while treatment T3A1 (15 brix x 3 days) gave the least extracted bioethanol from the fermented feedstock with an amount of $41.33 \mathrm{~mL}$. The results obtained are similar to the study conducted stating that the 
ethanol content increased with increasing fermentation time in both $27^{\circ} \mathrm{C}$ and $32^{\circ} \mathrm{C}$, though, the increase was higher at $32{ }^{\circ} \mathrm{C}$. The highest ethanol content was obtained on day 5 in temperature at $32^{\circ} \mathrm{C}(10)$.

Table 1 shows the obtained bioethanol using the reflux distiller using the combination of different days of fermentation and different sugar concentration. Analysis of Variance revealed significant differences on the extracted amount of bioethanol from different treatments. T1A3 and T3A1 were significantly different to all treatments. All other treatments were not significantly different from each other.

Table 1. Extracted bioethanol $(\mathrm{mL})$ from the feedstock.

\begin{tabular}{|c|c|c|c|c|c|c|}
\hline Treatment & R1 & $\mathbf{R 2}$ & $\mathbf{R 3}$ & Total & Mean & \\
\hline T1A1 (25 brix, 3 days) & 70.0 & 65.0 & 72.0 & 207.0 & 69.00 & $\mathrm{~d}$ \\
\hline T1A2 (25 brix, 5 days) & 92.0 & 87.0 & 85.0 & 264.0 & 88.00 & $\mathrm{bc}$ \\
\hline T1A3 (25 brix, 7 days) & 123 & 143 & 152.0 & 418.0 & 139.33 & $\mathrm{a}$ \\
\hline T2A1 (20 brix, 3 days) & 65.0 & 60.0 & 69.0 & 194.0 & 64.67 & ef \\
\hline T2A2 (20 brix, 5 days) & 75.0 & 72.0 & 80.0 & 227.0 & 75.67 & $\mathrm{~cd}$ \\
\hline T2A3 (20 brix, 7days) & 90.0 & 110 & 97.0 & 297.0 & 99.00 & $\mathrm{~b}$ \\
\hline T3A1 (15 brix, 3 days) & 40.0 & 45.0 & 39.0 & 124.0 & 41.33 & $\mathrm{~h}$ \\
\hline T3A2 (15 brix, 5 days) & 50.0 & 62.0 & 55.0 & 167.0 & 55.67 & $\mathrm{fg}$ \\
\hline T3A3 (15 brix, 7 days) & 65.0 & 72.0 & 70.0 & 207.0 & 69.00 & $\mathrm{de}$ \\
\hline Grand total & & & & 2105.0 & & \\
\hline
\end{tabular}

Note: Means with the same letter are not significantly different at 1\% level by DMRT.

Table 2 shows that the different level of sugar content has significant effect on the bioethanol produced. The treatment using 25 brix has the largest amount of bioethanol produced followed by 20 brix and 15 brix has the least amount of bioethanol produced. Also, the days of fermentation affect significantly on the amount of bioethanol extracted. Treatments under 7 days fermentation produced the largest amount of bioethanol. It is followed by 5 days fermentation and 3 days fermentation.

Table 2. Mean amount of bioethanol produced in mL.

\begin{tabular}{ccccccc}
\hline Treatment & A1 & A2 & A3 & Total & Mean & \\
\hline T1 & 207.0 & 264.0 & 418.0 & 889.0 & 296.3 & $\mathrm{a}$ \\
T2 & 194.0 & 227.0 & 297.0 & 718.0 & 239.3 & $\mathrm{~b}$ \\
T3 & 124.0 & 167.0 & 207.0 & 498.0 & 166.0 & $\mathrm{c}$ \\
Total & 525.0 & 658.0 & 922.0 & & & \\
\hline
\end{tabular}

Note: Means with the same letter are not significantly different at $1 \%$ level by DMRT.

The concentration of the extracted ethanol was measured using a hydrometer. The results of concentration ranges from $95 \%$ - 97\% due to the efficiency of the reflux distiller used in the study.

The bioethanol produced was lit using the lighter. The flame produced by the samples was blue which indicates complete combustion process. Figure 6 shows the flame produced from the extracted bioethanol.

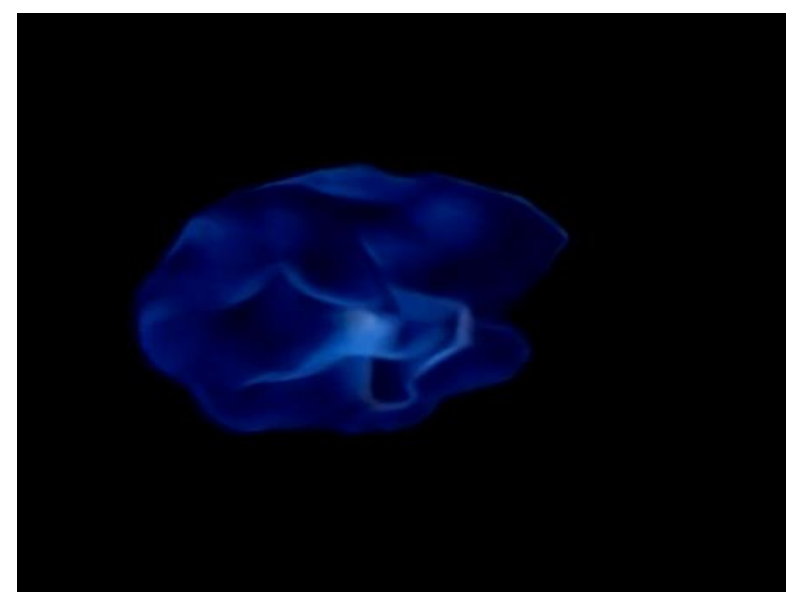

Figure 6. The flame produced by the extracted bioethanol.

The materials used in the extraction of bioethanol from golden shower fruit and the cost of production of bioethanol from golden shower fruit entailed an amount of Php50.89 in every liter of bioethanol obtained.

\section{Acknowledgment:}

The cooperation of the staff of the TAU SMART Agriculture Center is appreciated.

\section{Author's declaration:}

- Conflicts of Interest: None.

- I hereby confirm that all the Figures and Tables in the manuscript are mine. Besides, the Figures and images, which are not mine, have been given the permission for re-publication attached with the manuscript. 
- Ethical Clearance: The project was approved by the local ethical committee in Tarlac Agricultural University.

\section{References:}

1. Heux S, Sablayrolles JM, Cachon R, Dequin S. Engineering a Saccharomyces cerevisiae wine yeast that exhibits reduced ethanol production during fermentation under controlled microoxygenation conditions. Appl Environ Microbiol. 2006. Sep;72(9):5822-8

2. Cardona CA, Sanchez OJ. Fuel Ethanol Production: Process Design Trends and Integration Opportunities. Bioresour Technol. 2007 Sep;98(12):2415-57. doi: 10.1016/j.biortech.2007.01.002. Epub 2007 Mar 1. PMID: 17336061.

3. Miyashita M, Akamatsu M, Sakai K, Sakai H. Improving foam stability of ethanol/water mixture with anionic surfactant and long-chain alcohol. Chemistry Letters. 2020 May;49(5):453-456. https://doi.org/10.1246/cl.200058

4. Li H, Wu M, Xu L, Hou J, Guo T, Bao X, et al. Evaluation of industrial Saccharomyces cerevisiae strains as the chassis cell for second-generation bioethanol production. Microb Biotechnol. 2020. Mar;8(2):266-74. doi: 10.1111/1751-7915.12245.

5. Peter NM, Scheffran J, Widholm J. Designing Plants to Meet the Feedstock Needs. Plant Biotechnology for Sustainable Production of Energy and Coproducts. Springer Berlin Heidelberg; 2010. p. 57-84. ISBN 978-3-642-13440-1.

6. Goettemoeller J, Adrian G. Sustainable Ethanol: Biofuels, Biorefineries, Cellulosic Biomass, FlexFuel Vehicles, and Sustainable Farming for Energy Independence. 2017. p. 42. ISBN 978-0-9786293-0-4.

7. Gavin T, Sinnott R K. Chemical Engineering Design: Principles, Practice and Economics of Plant and Process Design. Butterworth-Heinemann. 2007. ISBN 0-7506-8423-2.

8. Amarasekara AS, Wiredu B. Sulfonic Acid Group Functionalized Ionic Liquid Catalyzed Hydrolysis of Cellulose in Water: Structure Activity Relationships. Sustainable Energy. 2014; 2(3):102-107. doi: 10.12691/rse-2-3-4..

9. Tamunaidu P, Matsui N, Okimori Y, Saka S. Nipa (Nypa fruticans) sap as a potential feedstock for ethanol production. Biomass \& Bioenergy, 52, 96102. 2013

10. Fahrizal F, Abubakar Y, Muzaifa M. The Effects of Temperature and Length of Fermentation on Bioethanol Production from Arenga Plant (Arenga pinnata MERR). 2016. Int J Adv Sci Eng Inf Technol 3(3):244.

\section{تحديد نوعية وكمية انتاج الايثانول الحيوي باستخدام فاكهة الدش الذهبي (ناسور كاسيا)}

$$
\text { إيمي ليزبيث ج.ريكو }
$$

كلية الهندسة و التكنولوجيا، تار لاك، الجامعة الزر اعية، الفلبين

يعد استتفاد الوقود الأحفوري أحد الأسباب الرئيسة ور اء انتشار الإيثانول الحيوي حيث إنه مصدر للطاقة المتجددة. ومن أجل تلبية

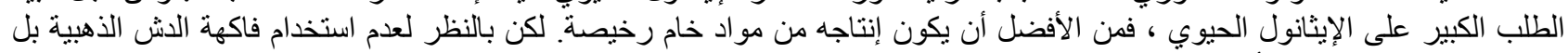

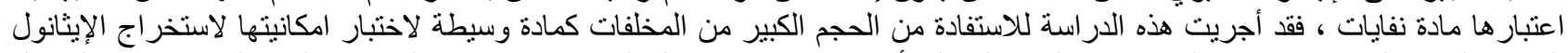

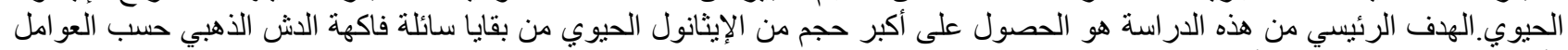

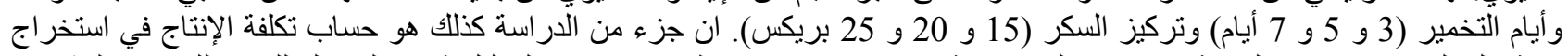
الإيثانول الحيوي من هذه الفاكهة.تم تكرار كل

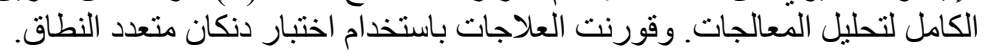

الكلمات المفتاحية: الايثانول الحيوي، الاستخر اج، التخمير ، الطاقة المتجدة، النفايات. 